\title{
Tipo de estaca e substrato na propagação vegetativa de Lippia gracilis Schauer
}

\section{Cutting type and substrate on vegetative propagation of Lippia gracilis Schauer}

\author{
Ricardo Gonçalves Santos ${ }^{1 *}$, lasmin Matias de Sousa ${ }^{2}$, Cynthia Cavalcanti de Albuquerque ${ }^{3}$, \\ Kathia Maria Barbosa e Silva ${ }^{3}$
}

||||||||||||||||||||||||||||||||||||||||||||||||||||||||||||||||||||||||||||||||||||||||||||||||||||||||||||||||||||||||||||||||||||||||||||||||||||||||||||||||||||||||||||||||||||||||||||||||||||||||||||||||||||||||||||||||||||||||||| |-

RESUMO: Lippia gracilis é uma planta nativa da Caatinga, rica em óleo essencial com atividade antimicrobiana. O trabalho objetivou avaliar o efeito de diferentes tipos de estacas e substratos na propagação vegetativa de L. gracilis. O experimento foi montado em delineamento inteiramente casualizado, em esquema fatorial 3 x 3 , sendo 3 tipos de estacas (apical, mediana e basal) e 3 tipos de substratos (areia + húmus, argila + húmus e areia + argila + húmus), com 5 repetiçóes cada. Aos 40 dias foram avaliadas: porcentagem de estacas brotadas e enraizadas, número médio de brotos, comprimento da maior raiz e biomassa seca dos brotos e raízes. Em todas as variáveis as estacas medianas e basais apresentaram melhores resultados do que as apicais. $\mathrm{O}$ substrato influenciou apenas na biomassa seca dos brotos, sendo o composto de argila + húmus superior ao areia + argila + húmus e igual, em significância, ao areia+ húmus.

PALAVRAS-CHAVE: Lippia gracilis Schauer; propagação vegetativa; estaquia; óleos essenciais.

\begin{abstract}
Lippia gracilis is a native plant of the Caatinga, it is rich in essential oil with antimicrobial activity. The study aimed to evaluate the effect of different types of cuttings and substrates on vegetative propagation of $L$. gracilis. The experimental design was completely randomized, in factorial scheme $3 \times 3$, with 3 types of cuttings (apical, median and basal) and 3 substrates (sand + humus, clay + humus and sand + clay + humus), with 5 replications each. After 40 days were evaluated: percentage of sprouted cuttings and rooted, average number of shoots, length of roots and dry biomass of shoots and roots. In all variables the middle and basal cuttings showed better results than the apical. The substrate influenced only in the dry biomass of shoots. The substrate composed of clay + humus was better than the sand + clay + humus and equal in significance to the sand + humus.
\end{abstract}

KEYWORDS: Lippia gracilis Schauer; vegetative propagation; cuttings; essential oils. 
Lippia gracilis Schauer, também conhecida como alecrim-da-chapada, alecrim-de-tabuleiro, alecrim-de-serrote ou cidreira-da-serra, pertencente à família Verbenaceae, é uma planta amplamente distribuída na regiáo Nordeste do Brasil, principalmente na Caatinga, devido à grande resistência a secas e altas temperaturas. É um arbusto caducifólio, ramificado, chegando até $3 \mathrm{~m}$ de altura, com flores brancas e folhas pequenas, altamente odoríferas, ricas em óleo essencial, composto principalmente por timol e carvacrol, que conferem atividade antimicrobiana, sendo por isso utilizada na medicina popular (PAscual et al., 2001; Albuquerque et al., 2006).

A propagaçáo da $L$. gracilis via semente torna-se inviável devido ao reduzido tamanho das sementes, o que dificulta sua coleta e manipulação, portanto, o uso de métodos de propagação como a estaquia apresenta-se como alternativa. Além disso, essa técnica pode permitir, em espécies aromáticas, a padronização da matéria-prima a partir da multiplicação de clones com alto teor de óleo essencial e níveis de seus constituintes majoritários.

A formação de raízes adventícias e o desenvolvimento das estacas dependem da interaçáo de fatores endógenos e das condiçóes ambientais proporcionadas ao enraizamento (Hartmann; Kester, 1990). Os tipos de propágulo e substrato são de extrema importância no estabelecimento das estacas. Segundo Pacheco; Franco (2008), a composição química do tecido da planta varia ao longo do ramo, dessa forma, estacas de diferentes porçóes tendem a diferir quanto ao enraizamento.

Substratos como areia, argila e húmus de minhoca possuem baixo custo de obtenção e podem ser livres de resíduos químicos. Atendendo às necessidades dos propágulos, essas características os tornariam viáveis para produção de L. gracilis por pequenos produtores, principalmente se essa produção for realizada em um sistema orgânico, o qual representa uma crescente demanda na produção de plantas medicinais e aromáticas.

Apesar dos vários relatos na literatura sobre a importância medicinal, bioquímica e ornamental das diversas espécies do gênero Lippia (Compadre et al., 1986; VAlentin et al., 1995; Pascual et al., 2001; Costa et al., 2002; Hennebelle et al., 2008; Guilhon et al., 2011), ainda há escassez de estudos direcionados à propagação vegetativa, especialmente quanto ao melhor tipo de propágulo e substrato para algumas espécies, como é o caso da L. gracilis.

Considerando a necessidade de informaçóes na literatura sobre a reprodução da $L$. gracilis e o elevado potencial fitoquímico e econômico que ela apresenta para a região semiárida do Nordeste brasileiro, torna-se necessário o desenvolvimento de pesquisas direcionadas para a propagação e avaliação do potencial produtivo dessa espécie sob condiçóes de cultivo. Conhecimentos sobre esses aspectos são importantes para fornecer subsídios para novas pesquisas e, ainda, abrir perspectivas para sua utilização na farmacologia.
Assim, este trabalho foi desenvolvido com o objetivo de avaliar o efeito do tipo de estaca e do substrato sobre a propagação vegetativa da $L$. gracilis.

O experimento foi conduzido a uma temperatura média de $27^{\circ} \mathrm{C}$ em ambiente de casa de vegetação com sombrite que permitiu a redução de $70 \%$ de luminosidade e irrigação com sistema automático de microaspersão (Rain Bird ${ }^{\circ}$ ), sendo acionada 4 vezes por dia com duraçáo de 10 minutos cada (turno de rega: $7 \mathrm{~h} 00 ; 10 \mathrm{~h} 00 ; 13 \mathrm{~h} 00$ e 16h00).

Como fonte de propágulo foram utilizadas estacas com aproximadamente $20 \mathrm{~cm}$ de comprimento contendo 2 gemas laterais. As estacas foram coletadas de plantas matrizes com 6 anos de idade localizadas no município de Mossoró, Rio Grande do Norte (coordenadas geográficas: latitude de $06^{\circ} 12^{\prime} 43^{\prime \prime}$ S e longitude de 37020'39” W). Em seguida, as estacas foram classificadas de acordo com a sua localização no ramo e espessura, sendo as médias do diâmetro de 4,1 mm; $8,3 \mathrm{~mm}$ e $16 \mathrm{~mm}$, para as estacas apicais, medianas e basais, respectivamente. Antes do plantio, as bases das estacas foram imersas em água por $24 \mathrm{~h} \mathrm{e}$, em seguida, foram plantadas em sacos de polietileno com capacidade para $1 \mathrm{~kg}$ contendo diferentes substratos: areia + húmus na proporçáo de 1:1, argila + húmus (1:1) e areia +argila + húmus (1:1:1).

Foi adotado um esquema fatorial $(3 \times 3)$ em delineamento experimental inteiramente casualizado, sendo os tratamentos resultantes da combinação entre os tipos de estacas (apical, mediana e basal) e os substratos (areia + húmus, argila + húmus e areia + argila + húmus). Cada tratamento consistiu de cinco repetiçóes com oito estacas.

Após 40 dias do estaqueamento foram avaliados: percentual de estacas brotadas e de enraizamento, número médio de brotos, comprimento da maior raiz (em centímetros) e biomassa seca dos brotos e das raízes (em gramas). Foi utilizada régua graduada para a mediçáo da maior raiz e, para a obtenção da biomassa seca, as folhas e raízes foram colocadas separadamente em sacos de papel craft e postas em estufa de circulação forçada de ar à temperatura de $65^{\circ} \mathrm{C}$ até a estabilização do peso, quando tiveram as massas determinadas por meio de balança digital semianalítica.

Os dados foram transformados em arco seno $\sqrt{\frac{x}{100}}$, uma vez que não apresentaram variâncias homogêneas pelo teste de Bartlett. Posteriormente, eles foram submetidos à análise de variância pelo teste $\mathrm{F}$ e comparados pelo teste de Tukey ao nível 5\% de probabilidade com o software Estat (UNESP, 1994).

Não se observou interação significativa entre os tipos de estacas testadas e os substratos no desenvolvimento de L. gracilis, porém, houve efeito significativo das estacas retiradas das diversas porçôes do ramo sobre todas as variáveis avaliadas e, dos substratos, apenas sobre a biomassa seca dos brotos. Apesar das estacas medianas e basais não diferirem estatisticamente entre si, apresentaram médias significativamente melhores em relação às estacas apicais (Tabela 1 ). 
No decorrer do experimento foi observado que as estacas retiradas da porção apical dos ramos emitiam os brotos mais rápido do que as demais, porém, a maioria náo completava o desenvolvimento e morria após a brotação. Já as estacas medianas e basais demoraram mais a emitir os primeiros brotos, no entanto, completavam o desenvolvimento, permanecendo vivas após a emissão de folhas e raízes. A morte das estacas apicais pode ter sido provocada pelo déficit de carboidratos, uma vez que tinham menor diâmetro e, consequentemente, as reservas estocadas podem não ter sido suficientes ao processo de enraizamento (Nicoloso et al., 1999) ou não houve a mobilização em tempo hábil para isso. A disponibilidade de carboidratos é um fator limitante para a sobrevivência das estacas, já que é a fonte básica de energia para o processo de enraizamento e metabolismo vegetal.

Tabela 1. Efeito do tipo de estaca e do substrato sobre o percentual de brotação, número médio de brotos, percentual de enraizamento, comprimento da maior raiz e biomassa seca dos brotos e raízes de alecrim-da-chapada (Lippia gracilis Schauer).

\begin{tabular}{|c|c|c|c|c|}
\hline \multirow{2}{*}{ Substrato } & \multicolumn{4}{|c|}{ Tipo de estaca } \\
\hline & Apical & Mediana & Basal & Média \\
\hline & \multicolumn{4}{|c|}{ Porcentagem de estacas brotadas* } \\
\hline Areia + húmus & 8,58 & 25,53 & 25,53 & $19,88^{\circ}$ \\
\hline Argila + húmus & 9,07 & 24,46 & 32,83 & $22,12^{\circ}$ \\
\hline Areia + argila + húmus & 5,17 & 26,01 & 14,82 & $15,33^{\circ}$ \\
\hline \multirow[t]{2}{*}{ Média } & $7,61^{\mathrm{B}}$ & $25,33^{A}$ & $24,39^{A}$ & \\
\hline & \multicolumn{4}{|c|}{ Número médio de brotos* } \\
\hline Areia + húmus & 4,85 & 12,10 & 12,60 & $9,85^{a}$ \\
\hline Argila + húmus & 8,08 & 16,26 & 12,85 & $12,40^{\circ}$ \\
\hline Areia + argila + húmus & 3,62 & 17,18 & 7,02 & $9,27^{a}$ \\
\hline \multirow[t]{2}{*}{ Média } & $5,52^{\mathrm{B}}$ & $15,18^{A}$ & $10,83^{\mathrm{A}}$ & \\
\hline & \multicolumn{4}{|c|}{ Porcentagem de enraizamento* } \\
\hline Areia + húmus & 8,58 & 23,98 & 25,53 & $19,36^{\circ}$ \\
\hline Argila + húmus & 9,07 & 22,60 & 27,87 & $19,85^{\circ}$ \\
\hline Areia + argila + húmus & 5,17 & 24,46 & 14,82 & $14,82^{\circ}$ \\
\hline \multirow[t]{2}{*}{ Média } & $7,61^{\mathrm{B}}$ & $23,68^{A}$ & $22,74^{A}$ & \\
\hline & \multicolumn{4}{|c|}{ Comprimento da maior raiz $(\mathrm{cm})^{*}$} \\
\hline Areia + húmus & 6,27 & 21,46 & 20,84 & $16,19^{\circ}$ \\
\hline Argila + húmus & 11,65 & 23,70 & 26,03 & $20,46^{\circ}$ \\
\hline Areia + argila + húmus & 5,75 & 25,26 & 15,79 & $15,60^{\circ}$ \\
\hline \multirow[t]{2}{*}{ Média } & $7,89^{\mathrm{B}}$ & $23,47^{A}$ & $20,89^{A}$ & \\
\hline & \multicolumn{4}{|c|}{ Biomassa seca dos brotos $(\mathrm{g})^{*}$} \\
\hline Areia + húmus & 1,62 & 1,98 & 2,47 & $2,02^{a b}$ \\
\hline Argila + húmus & 1,75 & 2,59 & 3,25 & $2,53^{a}$ \\
\hline Areia + argila + húmus & 1,40 & 2,23 & 1,76 & $1,80^{b}$ \\
\hline \multirow[t]{2}{*}{ Média } & $1,59^{\mathrm{B}}$ & $2,27^{A}$ & $2,49^{A}$ & \\
\hline & \multicolumn{4}{|c|}{ Biomassa seca das raízes $(\mathrm{g})^{*}$} \\
\hline Areia + húmus & 1,38 & 1,72 & 1,76 & $1,62^{\mathrm{a}}$ \\
\hline Argila + húmus & 1,50 & 1,83 & 2,11 & $1,82^{\mathrm{a}}$ \\
\hline Areia + argila + húmus & 1,38 & 1,94 & 1,58 & $1,64^{a}$ \\
\hline Média & $1,42^{B}$ & $1,83^{A}$ & $1,82^{A}$ & \\
\hline
\end{tabular}

*Médias seguidas pela mesma letra maiúscula na linha e minúscula na coluna não diferem significativamente entre si pelo teste de Tukey ao nível de $5 \%$ de probabilidade.
De acordo com Pacheco; Franco (2008), apesar das estacas grossas terem tecidos mais lignificados e com maior teor de peroxidases e ácido indolacético oxidase (AIA-oxidase), ambas envolvidas na degradação do ácido indolacético em conjugados inativos, estas podem ser beneficiadas pela maior disponibilidade de carboidrato armazenado.

Estacas com diâmetro maior podem acumular mais fotoassimilados, e esse fato pode corroborar os dados observados neste experimento, já que estacas medianas e basais (de diâmetro maior) apresentaram melhores resultados do que as apicais (de diâmetro menor) em todas as variáveis avaliadas (Tabela 1). Resultados semelhantes foram constatados por Biasi; Costa (2003) com a L. alba e Carvalho Júnior et al. (2009) com a L. sidoides. Esses autores perceberam que o aumento do comprimento da estaca lenhosa proporcionou melhor enraizamento.

Assim como o comprimento da estaca, o diâmetro também pode influenciar positivamente no desenvolvimento dos propágulos, do mesmo modo como observado neste trabalho, o que, segundo Pacheco; Franco (2008), é devido ao acúmulo de reservas nutritivas, o que potencializa as brotaçóes e o enraizamento. Outros autores, trabalhando com estaquia, observaram que estacas mais grossas apresentaram maior potencialidade para formação de raízes adventícias, como a exemplo de Dias et al. (1999), Frazon et al. (2004) e Fischer et al. (2008).

O desenvolvimento de estacas também é influenciado pela concentração de fitormônios, sobretudo das auxinas. Essa classe de reguladores de crescimento apresenta maior efeito na formação de raízes adventícias, pois ativa as células do câmbio, com importante funçâo na regulação do crescimento e desenvolvimento vegetal (Mercier, 2008).

A menor formaçẫo de brotos das estacas apicais pode ser devido à alta concentração de auxina endógena, que regula a dominância apical, inibindo o crescimento de gemas axilares (Tabela 1). Para Oliveira et al. (2011b), essa resposta deve estar relacionada à distância entre o ápice e a base do ramo, em virtude do significativo comprimento do mesmo. Chagas et al. (2008) explicaram que a remoção do ápice caulinar, normalmente, resulta no crescimento de gemas laterais, explicando a maior brotação nas estacas medianas e basais, devido à ausência da atividade auxínica, removida com o ápice. O corte impede a translocaçâo da auxina, fazendo com que as gemas laterais se desenvolvam.

Em relação ao tipo de substrato, apenas a biomassa seca dos brotos foi influenciada. Para essa variável, a composição argila + húmus foi mais eficiente do que a composiçấo areia + argila + húmus, não diferindo estatisticamente de areia + húmus (Tabela 1). É importante ressaltar que a maior biomassa da parte aérea pode se apresentar como um dos fatores fundamentais na emissão de raízes, visto que a produçâo de fitormônios, tal como ácido indolácetico, e de cofatores essenciais ao processo de enraizamento se dá através das folhas (HaRTMANN; Kester, 1990). O efeito positivo do substrato sobre a biomassa 
seca dos brotos pode estar relacionado especialmente com a porosidade, a qual afeta o teor de água retida e o seu equilíbrio com a aeração, o que, neste trabalho, foi possivelmente oferecido pelos substratos argila + húmus e areia + húmus.

Pode-se concluir que a propagação vegetativa de Lippia gracilis via estaquia é viável, sendo para isso recomendado o uso de estacas da porção mediana e basal dos ramos e, como substrato, uma composição de argila + húmus ou areia + húmus, ambos na proporção de 1:1. No entanto, devido ao baixo percentual de enraizamento apresentado por essa espécie, futuros experimentos devem ser conduzidos para complementar este estudo e contornar esse problema.

| | | | | | | | | | | | | | | | | | | | | | | | | | | | | | | | | | | | | | | | | | | | | | | | | | | | | | | | | | | | | | | | | | | | | | | | | | | | | | | | | | | | | | | | | | | | | | | | | | | | | | | | | | | | | | | | | | | | | | | | | | | | | | | | | | | | | | | | | | | | | | | | | | | | | | | | | | | | | | | | | | | | | | | | | | | | | | | | | | | | | | | | | | | | | | | | | | | | | | | | | | | | | | | | | | | | | | | REFERÊNCIAS

ALBUQUERQUE, C.C.; CAMARA, T.R.; MARIANO, R.L.R.; WILLADINO, L; MARCELINO JÚNIOR, C.; ULISSES, C. Antimicrobial action of the essential oil of Lippia gracilis Schauer. Brazilian Archives of Biology and Technology, Curitiba, v.49, n.4, p.527-535, 2006.

BIASI, L.A.; COSTA, G. Propagação vegetativa de Lippia alba. Ciência Rural, Santa Maria, v.33, n.3, p.455-459, 2003.

CARVALHO JÚNIOR, W.G.O.; MELO, M.T.P.; MARTINS, E.R. Comprimento da estaca no desenvolvimento de mudas de alecrim-pimenta. Ciência Rural, Santa Maria, v.39, n.7, p.21992202, 2009.

CHAGAS, J.H.; PINTO, J.E.B.P; BERTOLUCCI, S.K.V.; NALON, F.H. Produção de mudas de hortelã-japonesa em função da idade e de diferentes tipos de estaca. Ciência Rural, Santa Maria, v.38, n.8, p. 2157-2163, 2008.

COMPADRE, C.M.; ROBBINS, E.F.; KINGHORN, A.D. The intensely sweet herb, Lippia dulcis Trev.: historical uses, field inquires, and constituents. Journal of Ethnopharmacology, v.15, n. 1, p.89-106, 1986.

COSTA, S.M.O.; LEMOS, T.L.G.; PESSOA, O.D.L.; ASSUNÇÃO, J.C.C.; BRAZ-FILHO, R. Constituintes químicos de Lippia sidoides (Cham.) Verbenaceae. Revista Brasileira de Farmacognosia, Maringá, v.12, supl.1, p.66-67, 2002.

DIAS, R.M.S.L.; FRANCO, E.T.H.; DIAS, C.A.Enraizamento de estacas de diferentes diâmetros em Platanus acerifolia (Aiton) Willdenow. Ciência Florestal, Santa Maria, v.9, n.2, p.127-136, 1999.

FISCHER, D.L.O.; FACHINELLO, J.C.; ANTUNES, L.E.C.; TOMAZ, Z.F.P.; GIACOBBO, C.L. Efeito do ácido indolbutírico e da cultivar no enraizamento de estacas lenhosas de mirtilo. Revista Brasileira de Fruticultura, Jaboticabal, v.30, n.2, p.285-289, 2008.

FRAZON, R.C.; ANTUNES, L.E.C.; RASEIRA, M.C.B. Efeito do AIB e de diferentes tipos de estaca na propagação vegetativa de goiabeira-serrana (Acca selowiana Berg.). Revista Brasileira de Agrociência, v.10, n.4, p.515-518, 2004.

GUILHON, C.C.; RAYMUNDO, L.J.R.P.; ALVIANO, D.S.; BLANK, A.F.; ARRIGONI-BLANK, M.F.; MATHEUS, M.E.; CAVALCANTI,
S.C.H.; ALVIANO, C.S.; FERNANDES, P.D. Characterisation of the anti-inflammatory and antinociceptive activities and the mechanism of the action of Lippia gracilis essential oil. Journal of Ethnopharmacology, v.135, n.2, p.406-413, 2011.

HARTMANN, H.T.; KESTER, D.E. (Ed.). Propagation de plantas: princípios y practicas.Ciudad del México: Continental, 1990. 760p.

HENNEBELLE, T.; SAHPAZ, S.; JOSEPH, H.; BAILLEUL, F. Ethnopharmacology of Lippia alba. Journal of Ethnopharmacology, v.116, n.2, p.211-222, 2008.

MERCIER, H. Auxinas. In: KERBAUY, G.B. Fisiologia Vegetal. $2^{\mathrm{a}}$ ed. Rio de Janeiro: Guanabara Koogan, 2008. p.182-210. Cap. 9.

NICOLOSO, F.T.; FORTUNATO, R.P.; FOGAÇA, M.A.F. Influência da posiçãodaestacanoramosobreo enraizamento de Pfaffia glomerata (Spreng.) Pedersen em dois substratos. Ciência Rural, Santa Maria, v.29, n.2, p.277-283, 1999.

OLIVEIRA, L.M.; NEPOMUCENO, C.F; FREITAS, N.P; PEREIRA, D.M.S; SILVA, G.C; LUCCHESE, A.M. Propagação vegetativa de Hyptis leucocephala Mart. ex Benth. e Hyptis platanifolia Mart. ex Benth. (Lamiaceae). Revista Brasileira de Plantas Medicinais, Botucatu, v.13, n.1, p.73-78, 2011.

PACHECO, J.P.; FRANCO, E.T.H. Ácido indolbutírico em diferentes diâmetros na estaquia de Luehea divaricata. Ciência Rural, Santa Maria, v.38, n.6, p.1624-1629, 2008.

PASCUAL, M.E.; SLOWING, K.; CARRETERO, E.; SÁNCHEZMATA, D.; VILLAR, A. Lippia: traditional uses, chemistry and pharmacology: a review. Journal of Ethnopharmacology, v.76, n. 3, p.201-214, 2001.

UNIVERSIDADE ESTADUAL PAULISTA “JÚLIO DE MESQUITA FILHO” - UNESP. Departamento de Ciências Exatas. ESTAT. Versão 2.O.Jaboticabal: FCAV/UNESP, 1994.

VALENTIN, A.; PÉLISSIER, Y.; BENOIT, F.; MARION, C.; KONE, D.; MALLIE, M.; BASTIDE, J.; BESSIÈRE, J. Composition and antimalarial activity in vitro of volatile components of Lippia multiflora. Phytochemistry, v.40, n.5, p.1439-1442, 1995. 